\title{
Endocrine System Finding
}

National Cancer Institute

\section{Source}

National Cancer Institute. Endocrine System Finding. NCI Thesaurus. Code C36285.

Symptoms, physical examination results, and/or laboratory test results related to the endocrine system. 